
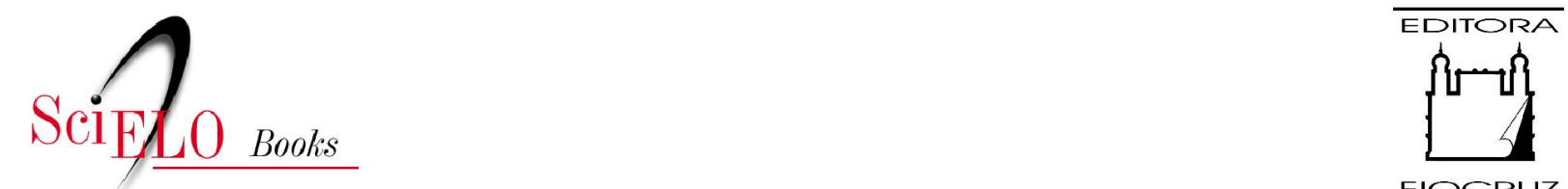

FIOCRUZ

\title{
2 Teorias, instituições, o fenômeno educativo e as redes
}

\author{
Tânia Celeste Matos Nunes
}

\section{SciELO Books / SciELO Livros / SciELO Libros}

NUNES, T. C. M. Teorias, instituições, o fenômeno educativo e as redes. In: Democracia no ensino e nas instituições: a face pedagógica do SUS [online]. Rio de Janeiro: Editora FIOCRUZ, 2007, pp. 4769. ISBN: 978-85-7541-530-6. Available from: doi: 10.7476/9788575415306. Also available in ePUB from: http://books.scielo.org/id/7p3wt/epub/nunes-9788575415306.epub.

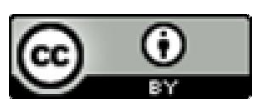

All the contents of this work, except where otherwise noted, is licensed under a Creative Commons Attribution $\underline{4.0 \text { International license. }}$

Todo o conteúdo deste trabalho, exceto quando houver ressalva, é publicado sob a licença Creative Commons Atribição 4.0.

Todo el contenido de esta obra, excepto donde se indique lo contrario, está bajo licencia de la licencia Creative Commons Reconocimento 4.0. 


\section{Teorias, Instituições, o Fênomeno Educativo e as Redes}

A organização do sistema de saúde brasileiro, bem como os diferentes projetos de reforma e de reestruturação do modelo de atenção à saúde que se sistematizam a partir da década de 70 compõem uma das searas de debates e temas relevantes para entender as propostas de ensino de saúde pública no Brasil. As conexões destes debates e propostas acerca da organização dos serviços de saúde e as reformas no campo do ensino de saúde pública não poderão, contudo, a nosso juízo, ser entendidas de forma mecânica, como se o ensino estivesse a reboque das propostas da saúde.

O campo da educação compõe uma arena específica, com suas premissas, debates teóricos e propostas particulares, compondo assim um eixo próprio de análise que, ainda que possa (e tenha de) ser remetido às discussões sobre as necessidades organizacionais do sistema de saúde brasileiro, não pode ser tratado como epifenômeno destas.

A noção de 'centro escolar', por exemplo, é fundamental neste estudo. Em parte pelo caráter acolhedor que essas instituições apresentam em relação aos fenômenos estudados, proporcionando arranjos peculiares que dão corpo e legitimidade às experiências de cursos e demais programas de ensino, expressando-se em processos formais, em registros de atividades formalmente organizadas e processos de avaliação. Pelo potencial de dinamismo de suas atividades, os centros escolares podem se revelar mais ou menos engajados nas conjunturas correspondentes, posturas que se refletem em seus projetos e suas programações de atividades.

o dinamismo dos centros escolares, por sua vez, nos convida a refletir sobre o papel que tais instituições podem, em maior ou menor grau, ter desempenhado em contextos históricos específicos. Uma reflexão neste sentido poderá contribuir para subsidiar o entendimento de fatos e processos da conjuntura 
estudada, movendo grupos e mobilizando investimentos e articulações que possam ter resultado em produtos, como disciplinas e cursos inovadores, com a incorporação de conteúdos representativos de um olhar engajado e que contribuíram para ressignificar o ensino da saúde pública no país. Afinal, como foi possível, em um período marcadamente hostil de repressão política e patrulha ideológica, que propostas inovadoras e progressistas para os campos da saúde e da educação brasileiros não apenas surgissem, mas sobretudo se institucionalizassem como políticas oficiais?

\section{Do poder da instituição à instituição do poder}

O recorte assumido por este estudo demanda um esforço analítico de compreensão de diferentes estruturas, seja o espaço atinente ao campo da educação, seja ao do campo da saúde. Incluímos, aqui, suas distintas dimensões político-administrativas, nos diferentes níveis: municipal, estadual e federal. Trata-se ainda de estruturas temporais, tendo em vista o amplo cenário de mudanças pelo qual passava o país naquele período.

Nesse sentido, o pensamento de Testa (1997) sobre tempo histórico e tempo cronológico parece exemplar para representar a ação humana em um determinado tempo que se acelera, permitindo a produção de fatos e processos no espaço em que a história se constrói. Para ele, "o tempo histórico é incompreensível sem os aceleramentos e atrasos que lhe imprimem à ação humana e que o transformam assim em equivalente à transformação da contradição em conflito" (Testa, 1997: 45). ${ }^{8}$

Esse conceito se contrapõe ao de tempo cronológico, cujos ritmos estão ligados à reprodução cotidiana das instituições e também à produção de objetos. O que viabiliza o produto das instituições é também a síntese contraditória dos tempos históricos e cronológicos, orientando os processos de trabalho das equipes técnicas e administrativas e demais atores sociais, e as relações que se estabelecem com suas correspondentes estruturas regulatórias (conselhos de ensino, reitorias), contribuindo também para entender a formação dessas equipes e seus correspondentes graus de organização, traduzidos na qualidade de ensino do período.

A noção de tempo histórico de Testa facilita a compreensão de processos institucionais que permitem o diálogo permanente entre as suas propostas e outros espaços da vida em sociedade, favorecendo a formulação de programas

\footnotetext{
${ }^{8}$ Todas as citações de Testa (1997) foram traduzidas pela autora.
} 
peculiares de ensino e de escolas, como "espaço inacabado e em gestação permanente" (Kononovich \& Saidón, 1991: 39).

Estas noções parecem oportunas para analisar as conjunturas que conformam o período estudado. Além disso, ao compreendermos as instituições como a "formalização das organizações (a parceria, o processo de trabalho, a discussão pública), as quais, por sua vez, são os núcleos sólidos da atividade social" (Testa,1997: 57), corroboramos o entendimento de que a

instituição se define mediante uma maneira de comportar-se segundo as normas institucionais, a ausência ou o desconhecimento delas, tanto que a organização é a forma de abrigar a estrutura das relações entre pessoas, para a realização de uma tarefa ou o cumprimento de uma função. (Testa, 1997: 57-58)

Testa destaca o processo de trabalho e o comportamento institucional como duas vertentes importantes para caracterizar as instituições. Sobre este aspecto, ele interroga qual dos dois componentes cumpriria o papel de instituinte e se posiciona afirmando que não haveria "uma solução única para esse dilema", tendo em vista o fato de que o instituinte, em contextos históricos precisos, poderia desempenhar comportamentos críticos, tornando-se assim ele mesmo agente de mudanças institucionais e da sociedade como um todo. E conclui, refletindo que "é através dessas modificações que se produzem as mudanças sociais viáveis” (Testa, 1997: 58).

Nessa discussão, o autor também critica a interpretação de que a estrutura é o pólo conservador e que a organização, o pólo dinâmico. Para ele, as estruturas são dinâmicas e dinamizadoras, onde a contradição se estabelece entre o dinamismo da organização e a elasticidade da Instituição, cujo fundamento é mais a legalidade estabilizadora que a legitimidade justificadora de sua existência. Em consonância com isso, nos fala Testa (1997: 59-60), "devemos recordar que a legitimidade é precisamente, o que constrói o instituinte, enquanto que a legalidade é o que estabiliza o instituído".

$\mathrm{O}$ autor defende também que:

a legitimidade se constrói mediante um processo social, o que implica a atividade de atores que nele se conformam (não há atores legitimadores pré-formados), enquanto a legalidade se adquire através de um ato pontual em que os atores formais existentes sancionam o status de legal. (Testa, 1997: 60)

Para ele, o conceito de legítimo recorda a "hegemonia" no pensamento do último Gramsci, o que corresponde a uma liderança política, intelectual e moral, elemento central da construção de viabilidade de um projeto.

Uma outra vertente dessa discussão articula a relação da instituição com saberes e estruturas e está relacionada ao campo da análise institucional, que 
"considera os saberes como instituições sem estabelecimento, sem espaço aparente ou manifesto" (Kononovich \& Saidón, 1991: 37). Segundo os autores, a dinâmica dessas instituições se realiza questionando o lugar e o espaço do especialista. Kononovich e Saidón (1991: 37) destacam ainda que tais espaços estão atravessados por práticas que "a especialização e as disciplinas intentam recortar e controlar fora de seu campo". Esse conceito realiza a crítica da idéia formulada pela psicologia social de "estabelecimento como o lugar que organiza as diferentes ações e intercâmbios dos membros de uma instituição" e aproxima-se da corrente socioanalítica, concluindo que "a analogia que se produz entre 'estabelecimento' e 'instituição' impede captar o sentido das forças instituintes que dão lugar ao instituído. A instituição não se define mais como um lugar, mas como uma relação entre instituído e instituinte" (Kononovich \& Saidón, 1991: 39).

A crítica dos autores à visão de instituição com características rígidas aponta para uma formulação que lhe conforma como "um espaço contraditório, atravessado por forças que escapam aos limites que estão fixados pela física do estabelecimento" (Kononovich \& Saidón, 1991:39). Abre-se, assim, a perspectiva de que no interior das instituições, mesmo aquelas mais conservadoras ou ditatorialmente controladas, existam intenções e permitam a formulação de projetos a priori não afinados às diretrizes oficiais ou dominantes.

A partir dessas formulações, entendemos as instituições como espaços de construção e experimentação de práticas sociais, com segmentos abertos e fechados para a realização de inovações. São espaços de poder e campos de forças que estão distribuídos em estruturas flexíveis, capazes de dialogar com os campos relacionais, podendo abrigar ideologias diversas, assim como tensões em torno de idéias e projetos, portanto, um campo fértil para a criação.

Esse entendimento se relaciona com uma outra face dessa discussão representada pela noção de poder. Para Luz (1981: 32), o poder se apresenta "como estrutura normalizante de relações sociais de subordinação", o que, na consideração da autora, "não é como se apresenta em sua face de Ordem, organização integrada de práticas, unidade discursiva coerente. Seu discurso é composto de várias razões. Suas normas, a proposta de unificar interesses diversos, relações conflituosas". Dessa forma, pode-se considerar que as "brechas', entendidas como espaços de movimentação das equipes que permearam os espaços políticos institucionais no período estudado, permitiram o surgimento de múltiplas experiências traduzidas em práticas de ensino, no interior dos centros escolares dedicados à formação dos sanitaristas, ainda que, como é o nosso caso, algumas destas práticas não fizessem parte a priori do escopo das metas propostas pelo establishment do Estado brasileiro. 
Essa discussão nos leva mais uma vez à análise de Testa (1992) sobre o papel do Estado nas formações sociais capitalistas, em dois níveis de agregação:

o que é caracterizado por seu funcionamento de conjunto homogêneo, e o que revela suas contradições internas, com diferentes graus de heterogeneidade. No primeiro desses níveis, o principal papel das Instituições de Estado é o de garantir a continuidade do sistema capitalista, e, na medida do possível, a relação das contradições geradas dentro dos grupos dominantes. No segundo nível de agregação, surgem elementos de heterogeneidade dentro das Instituições do Estado que podem dar lugar a contradições que levam à criação de condições favoráveis ao desenvolvimento ou ao fortalecimento dos conflitos interclasses. (Testa, 1992: 111-112)

Pela característica deste estudo, que se expressa na confluência das instituições de saúde e educação com seus respectivos processos de trabalho, parece importante considerar a existência de três poderes expressos nas práticas de saúde. Na perspectiva de Testa (1992: 118), há o

Poder técnico, referente à capacidade de gerar, aceder e lidar com a informação de características diferentes; o Poder administrativo, relativo à capacidade de se apropriar e de atribuir recursos e, por fim, o Poder político, cujo papel se situa na capacidade de mobilizar grupos sociais em demanda ou reclamação de suas necessidades ou interesses.

A convivência entre os poderes está na raiz do processo de trabalho dos profissionais que estão nos centros escolares, expressam-se nas relações das equipes de saúde e de gestão da saúde, e dessas com a população. As maneiras como se combinam os tipos de poder e as formas assumidas sugerem que tipos e formas não são jamais estáticos, se transformam uns em outros, de maneira a permitir determinada autonomia no arranjo dos processos locais, assinalando também o caminho que se teria de percorrer para a constituição de um poder político de classe, isto é, de um poder político científico e pretensamente hegemônico.

Vale destacar que, a partir do final da década de 60 e início dos anos 70 , o governo tentou implantar um discurso hegemônico na saúde, "enquanto setor de Estado, cujo efeito político mais importante é o de excluir, enquanto projeto político institucional alternativo, todo e qualquer outro discurso que não tenha a sua razão, sua racionalidade" (Luz, 1981: 15). Para alcançar esses objetivos, no período, o governo promoveu a integração do 'discurso médico' ao do desenvolvimento econômico, operou a centralização de órgãos e instituições de saúde e imprimiu o controle do poder decisório em altos escalóes da hierarquia burocrática institucional. 
Essa mesma autora, no entanto, propõe "analisar as relações do ponto de vista dialético, buscando no coração da ordem, aquilo que constantemente a ameaça" (Luz, 1981: 32). E complementa, considerando que:

se só existe estrutura entendida como conjunto de regras mais ou menos rigidamente hierarquizadas, na medida em que ela é organização de relações sociais de poder, essas relações de poder são a prática de certas regras do jogo. São, portanto, práticas institucionais. Enquanto prática que institui a dominação como ordem, a prática institucional tende a ser conflituosa (vista do ângulo das relações sociais) e contraditória (vista do ângulo da estrutura). (Luz, 1981: 35)

A fertilização de idéias produzidas no âmbito das instituições de saúde no período estudado impõe um questionamento quanto à capacidade de produzir inovações e viabilizar propostas nas instituições de governo, estruturadas pela lógica da "dominação como ordem" (Luz, 1981).

Parece pertinente recorrer, novamente, ao pensamento de Testa (1997: 24-25), que identifica o processo de construção de viabilidade dos projetos com os processos de construção de sujeitos sociais e acrescenta que "a transição da ditadura para a democracia determinou o aparecimento de uma institucionalidade e uma metodologia diferentes, para a realização dos novos propósitos". O autor destaca "a imaturidade das instituições estatais naquele momento para determinar seus propósitos" (Testa, 1992: 114), o que, em nosso entendimento, poderia ser um fator de ampliação do campo de possibilidades para o surgimento de inovações e para a construção de alianças entre grupos e instituições.

Em nossa consideração, o poder poderá ser representado pela compreensão do exercício da autoridade, fruto de relações sociais, de natureza conflituosa e contraditória, capaz de impulsionar processos de coerção, força, manipulação e autorização, dentre outros, e cujo exercício implica decisões entre modos alternativos de decisão, isto é, não há uma única matriz de autoridade que determina o comportamento dos atores sociais, mesmo dentro de instituições burocráticas reguladas pela autoridade do estado. ${ }^{9}$

Dito de outro modo, a margem de decisões posta fora da matriz de poder institucional não é desprezível, constitui uma arena importante de tomada de decisões burocráticas e políticas, que se desdobram, muitas vezes, em programas e produtos oficiais, tais como disciplinas e cursos inovadores, com a

\footnotetext{
${ }^{9}$ Para uma visão das diferentes conceituações e escolas de pensamento acerca do poder, recomenda-se Lukes (1980). Este autor faz uma síntese da visão de pensadores sobre o poder, destacando Parsons, Arendt, Giddens entre outros, como personagens representativos de diferentes visões sociológicas: a unidimensional ou pluralista, a bidimensional e a tridimensional. o debate sumarizado por Lukes permite revelar as diversas conceituações que revestem o poder nas organizações e na sociedade.
} 
incorporação de conteúdos representativos de um olhar engajado e, neste sentido, fora da base ideológica do sistema político-ideológico oficial. Estas brechas do sistema instituído possibilitaram ao movimento quase organizado pela democracia na saúde, construir alternativas de contribuição para a ressignificação do ensino da saúde pública no país.

\section{Das teorias aos atos: o fenômeno educativo}

O espírito de luta presente nos mais diferentes grupos sociais que se opunham ao regime político ditatorial iniciado nos anos 60 se expressou em um movimento de mudança e ruptura política bastante fértil que atingiu vários campos da sociedade brasileira. Uma de suas expressões foram os cursos e os programas de Seminários desenvolvidos nas universidades que refletiam, por sua vez, a reconfiguração do campo da saúde pública, como veremos mais adiante, sob a mediação da Associação Brasileira de Pós-Graduação em Saúde Coletiva (Abrasco) e do Centro Brasileiro de Estudos de Saúde (Cebes), durante a década de 80 .

A compreensão da materialidade desses processos também requer uma leitura que possa ir além dos recortes disciplinares da saúde. As evidências que se configuram no conjunto de disciplinas e dos programas de formação, que passam por transformações no período, devem ser entendidas também a partir das leituras que se filiam ao campo da educação, pelo caráter mais ou menos conservador ou mesmo libertário das correntes educacionais. Elas se constituem em contribuições importantes para entender a escolha de processos ousados de formação, vocalizados, por exemplo, no rompimento das fronteiras das duas escolas aqui estudadas, que logo se comprometeram com um processo de formação de um sanitarista crítico - frente aos padróes da época - que se expandiria para diferentes estados do país. Nessa dimensão, o processo educacional se constitui em uma vertente importante deste estudo, expressando-se em alternativas pedagógicas referidas aos centros formadores em suas relações internas (programas e docentes) e externas (parceiros do sistema de saúde ou do sistema de formação), demandando uma incursão nas teorias educacionais e seus desdobramentos, como reflexão teórica tanto do processo educativo, como constituinte do campo da educação.

Para melhor compreender os debates das teorias educacionais, os estudos de Dermeval Saviani (1994) e Bárbara Freitag (1980) contribuem de forma ilustrativa quando apresentam suas leituras sobre o tema, pelas análises do fenômeno da marginalidade e da política educacional brasileira, respectivamente.

Saviani categoriza inicialmente as teorias educacionais em duas vertentes: a que entende a educação como "instrumento de equalização social" e a 
que interpreta a educação como um "instrumento de discriminação social", ressaltando que ambos relacionam educação com sociedade, superando uma visão ingênua da educação como prática pedagógica desprovida de intencionalidade política.

$\mathrm{Na}$ análise de Freitag, quase todos os autores que discutem a conceituação da educação e sua relação com o contexto social concordam em dois pontos: o de que a educação sempre expressa uma doutrina pedagógica, a qual, implícita ou explicitamente, se baseia em uma filosofia de vida, concepção de homem e sociedade; e um outro, indicativo de que "numa realidade social concreta, o processo educacional se dá através de instituições específicas (família, igreja, escola, comunidade) que se tornam porta-vozes de uma determinada doutrina pedagógica" (Freitag,1980: 15).

Saviani classifica as teorias da educação em não críticas, crítico-reprodutivistas e críticas. Entre as primeiras, estão a pedagogia tradicional, a pedagogia nova e a pedagogia tecnicista. Todas elas entendem a educação como um instrumento para "converter súditos em cidadãos" e lhe atribuem a função de "equalização social". Têm entre si diferenças que valem a pena ser destacadas, pela natureza das intervenções que propõem no processo educativo.

$\mathrm{Na}$ proposta tradicional, a escola se organiza como "agência centrada no professor, que transmite o acervo ao aluno segundo uma gradação lógica" (Saviani, 1994: 18). Os alunos são atentos, organizados em classes, cada uma com seu respectivo professor. Este modelo, é importante salientar, se reproduziu vivamente não apenas no ensino básico e fundamental, constituindo-se também como elemento estruturador do ensino das profissões de nível superior, incluindo aquelas das ciências da saúde.

A 'pedagogia nova' ou movimento escolanovismo se propõe a superar a tradicional,

deslocando o eixo da questão pedagógica, do intelecto para o sentimento; do aspecto lógico para o psicológico; dos conteúdos cognitivos para os métodos ou processos pedagógicos; do professor para o aluno; do esforço para o interesse; da disciplina para a espontaneidade; do diretivismo para o não diretivismo; da quantidade para a qualidade; de uma pedagogia de inspiração filosófica centrada na ciência da lógica, para uma pedagogia de inspiração experimental, baseada, principalmente, nas contribuições da biologia e da psicologia. (Saviani, 1994: 20)

Esta seria uma escola alegre, colorida, barulhenta e movimentada, tendo no professor um grande estimulador da aprendizagem, que se relacionaria com um grupo pequeno de alunos. Suas bibliotecas seriam dotadas de materiais didáticos ricos. 
A pedagogia tecnicista aparece na metade do século XX, quando as esperanças no escolanovismo foram frustradas. Aqui:

o elemento principal passa a ser a organização racional dos meios, ocupando professor e aluno posição secundária, relegados que são à condição de executores de um processo cuja concepção, planejamento, coordenação e controle ficam a cargo de especialistas supostamente habilitados, neutros, objetivos e imparciais. (Saviani, 1994:24)

A conseqüência na organização do trabalho é o crescente processo de burocratização e um investimento maciço nas atividades meio em detrimento da atividade fim. Saviani elabora uma síntese das propostas pedagógicas, referindo-se à tradicional como o "aprender", a pedagogia nova como "aprender a aprender" e a tecnicista seria o "aprender a fazer".

As teorias crítico-reprodutivistas representam aquelas que vinculam invariavelmente a educação à reprodução da sociedade de classes e ao reforço do modo de produção capitalista. Nesse bloco, estão as teorias do sistema de ensino como violência simbólica (Bourdieu e Passeron), da escola como aparelho ideológico de Estado (Althusser) e da escola dualista (Baudelot e Establet). A teoria do sistema de ensino como violência simbólica, desenvolvida na obra de Bourdieu e Passeron, em 1975, traduz a ação pedagógica "como imposição arbitrária da cultura (também arbitrária) dos grupos ou classes dominantes aos grupos ou classes dominadas" (Saviani, 1994: 30). "Uma das funções se manifesta no mundo das representações simbólicas (Bourdieu) ou ideologia, a outra atua na própria realidade social". Segundo Bourdieu, "o sistema educacional garante a transmissão hereditária do poder e dos privilégios, dissimulando sob a aparência da neutralidade o cumprimento dessa função" (apud Freitag, 1980: 25).

Na compreensão de Saviani, Althusser desenvolve sua contribuição à discussão, partindo da existência de aparelhos repressivos e ideológicos de Estado, classificando, entre os primeiros, o governo, a administração, o exército, a polícia, os tribunais, as prisões, e entre os ideológicos inclui o religioso, escolar, familiar, jurídico, político, sindical, da informação e da cultura, e atribui à escola "a função básica de reprodução das relações materiais e sociais de produção" (Freitag, 1980: 33). Para Saviani (1994: 35), Althusser "chega mesmo a afirmar que os aparelhos ideológicos do Estado podem ser não só o alvo, mas também o local da luta de classes".

A Teoria da Escola Dualista elege "a inculcação da ideologia burguesa" (Saviani, 1994: 37) como papel fundamental da escola. Seus autores consideram que é aparente a visão de escola unitária e unificadora, concluindo pela existência de duas redes de escolarização, correspondentes à divisão da soci- 
edade capitalista em classes: a burguesia e o proletariado. Essas estariam representadas, segundo a teoria dualista, em "rede secundária superior" e "rede primária profissional". Ainda que admita a escola no quadro da luta de classes, a teoria da escola dualista não a considera "como palco e alvo" dessa mesma luta.

Uma outra síntese das visões da educação foi realizada por Freitag abordando um conjunto de autores que discutem o processo educacional, iniciando por Durkheim, que "parte do homem egoísta, que precisa ser moldado para a vida societária", acreditando que "novas gerações aprendem com gerações mais velhas, num processo educacional mediatizado pela família, mas também pela Escola e pela Universidade" (Freitag, 1980: 16). Talcott Parsons acrescenta a questão da socialização, afirmando que "sem ela, o sistema social é incapaz de manter-se integrado, preservar sua ordem, seu equilíbrio e conservar seus limites" (apud Freitag, 1980: 16).

Freitag considera que Dewey e Mannheim criticam a visão da educação como um mecanismo de correção e ajustamento do indivíduo e consideram que a estrutura poderá desempenhar um papel dinamizador, a partir do ato inovador do indivíduo. Nessa proposta, segundo Dewey, a escola deve assumir características de uma pequena comunidade democrática, onde a criança aprende as práticas da democracia pelas próprias vivências, "habilitando-se a transferi-las, futuramente em sua vida adulta, à sociedade democrática como tal" (Freitag, 1980: 19). Freitag critica Durkheim e Parsons, considerando que ambos negam a dimensão histórica, negam a dimensão inovadora e emancipatória da educação, expelem os conflitos e as contradições de seus modelos teóricos e postulam ser o sistema educacional o mecanismo de ajustamento por excelência, entre indivíduo e sociedade.

Sobre Dewey e Mannheim, a crítica da autora ressalva que ambos compreendem a educação como um instrumento de mudança social, mas a coloca na mesma visão conservadora de Durkheim e Parsons. Para ela, estes autores definem como objetivo final da educação, uma "sociedade democrática harmoniosa, em que reina a ordem e tranqüilidade, onde conflitos e contradições encontram seus mecanismos de solução e canalização" (Freitag, 1980: 24).

A revisão do pensamento de Durkheim e Parsons se complementa com uma síntese de Bourdieu, que atribui à escola uma "função de reprodução cultural e social" que "reproduz as relações sociais de produção da sociedade capitalista" (Freitag, 1980: 27), e cuja afirmação é assim questionada pela autora:

mas seria isso somente? Suas funções realmente se limitam à reprodução cultural e social das relações sociais? Se assim fosse, como se justificariam as investidas e interferências das empresas e do Estado na esfera educacional, com a intenção de aprimorar recursos humanos, e refuncionalizar o sistema educacional? (Freitag, 1980: 27) 
As perguntas elaboradas por Freitag introduzem uma vertente da educação muito utilizada pelo campo da saúde desde o final da década de 70 , que discute a formação de recursos humanos, vinculada a processos de expansão e requalificação do setor. Em sua dimensão reflexiva do processo de formação, a questão dos recursos humanos para a saúde é discutida por Paim (1994) como um tema complexo para o sistema de saúde brasileiro que envolve as instituições educativas e de serviços, as corporações profissionais, e os movimentos populares, dentre outros.

Recorrendo mais uma vez às leituras de Freitag, vamos encontrar a recuperação do pensamento de autores como Becker, Schutz, Edding e Solow, que, em suas respectivas obras, são os pais das disciplinas de planejamento educacional e economia da educação, que embasaram muitas das propostas de organização do tema de recursos humanos nas organizações, no setor público ou privado, no período estudado. Para a autora, "eles partem de uma constatação empírica que fundamenta suas reflexões teóricas: a alta correlação entre crescimento econômico e nível educacional dos membros de uma sociedade dada" (Freitag, 1980: 28).

$\mathrm{Na}$ busca pelo entendimento dessa questão, os formuladores da área da educação se aproximaram da economia, valorizaram a discussão sobre a relação entre capital e trabalho, e, através de Becker e Schutz, formularam a hipótese da educação como taxa de crescimento excedente. Tendo essa hipótese como válida, os investimentos econômicos rentáveis seriam aqueles voltados para a população ativa. "Desde então, se vem falando de recursos humanos, formação do capital humano e formação de manpower" (Freitag, 1980: 28). Nessa concepção, "o investimento é feito em nome da nação, produzindo uma taxa de crescimento que beneficia a todos" logo, "os cofres públicos podem e devem arcar com as despesas" (Freitag, 1980: 27-28).

Considerando que os gastos educacionais devem ser feitos com um mínimo de desperdício, a economia da educação recorreu ao planejamento educacional, efetuando uma composição entre os dois modelos clássicos da economia e da educação: os modelos do investimento e da demanda, respectivamente.

A leitura de Freitag (1980: 28) inclui ainda o pensamento de Altvater, que considera que "há de fato uma socialização dos gastos educacionais, mediatizada pelo Estado, no interesse da empresa privada e do capital monopolístico". $\mathrm{E}$ ainda adverte que os investimentos realizados para aprimorar a força de trabalho, sob a forma declarada de qualificação de mão-de-obra e aperfeiçoamento dos recursos humanos, precisam ser observados no próprio contexto da produção capitalista. Nesse sentido,

os investimentos educacionais vistos no contexto da reprodução ampliada precisam ser compreendidos como investimentos em capital variável, que tornará mais 
eficientes investimentos em capital constante, aumentando com isso a produtividade do processo de produção e reprodução capitalista. (Freitag, 1980: 29)

A partir da análise de que as teorias crítico reprodutivas estão apenas empenhadas em explicar o mecanismo de funcionamento da escola tal como está constituída, Saviani avançou na construção de uma teoria crítica da educação, formulando, para isso, uma série de interrogações, vinculadas à temática da marginalidade: é possível articular a escola com os interesses dominados? É possível uma teoria da educação que capte criticamente a escola como um instrumento capaz de contribuir para a superação do problema da marginalidade?

0 autor conclui pela necessidade de superar "tanto o poder ilusório (que caracteriza as teorias não críticas), como a impotência (decorrente das teorias crítico-reprodutivistas), colocando nas mãos dos educadores uma arma de luta capaz de permitir-lhes o exercício de um poder real, ainda que limitado" (Saviani, 1994: 41). Reconhecendo que esse é um caminho repleto de armadilhas, onde "os mecanismos acionados periodicamente a partir dos interesses dominantes podem ser confundidos com os anseios da classe dominada", Saviani (1994: 42) propõe que a educação mergulhe na sua especificidade, como um caminho que a "levará à compreensão das complexas mediações pelas quais se dá a sua inserção contraditória na sociedade capitalista".

Na dimensão formulativa, Paulo Freire (1979) propõe a educação problematizadora, a partir da crítica à "educação bancária", cujos conhecimentos são despejados do educando para o educador. Freire apresenta sua proposta como "futuridade revolucionária", que se identifica como um "movimento permanente em que se acham inscritos os homens, como seres que se sabem inconclusos"; considera que "o movimento é histórico e que tem o seu ponto de partida, o seu sujeito, o seu objetivo". Nessa concepção,

os homens são entendidos como seres históricos (...) como seres mais além de si mesmos - como "projetos" - como seres que caminham para a frente, que olham para frente; como seres a quem o imobilismo ameaça de morte; para quem o olhar para traz não deve ser uma forma nostálgica de querer voltar, mas um modo de melhor conhecer o que está sendo, para melhor construir o futuro. (Freire, 1979: 84)

Em Cury, vamos encontrar uma estreita vinculação da educação com o processo educativo formal, constituindo-se num terceiro modo de abordá-la no seu caráter mediador propositivo, e que reconhece os homens como agentes históricos e não como "meros produtos sociais" (Cury, 1995: 53). Apresentando a educação com gênero e função específica, o autor ressalva que ela "é produto humano e conservará o caráter dialético dos fenômenos existentes na estrutura social", que por sua vez, "geram novas exigências para a educação, que, 
ao captá-las, antecipa um modo de ser futuro, que determina tarefas para o presente" (Cury, 1995: 54). Desse modo,

as relações de dominação (e dentro delas a educação) só contribuem efetivamente para a reprodução das relações sociais e sua consolidação, caso se tornem elementos mediadores entre a estrutura econômica capitalista e a conquista de um espaço: o da consciência e do saber, ambos transformados em forças produtivas. (Cury, 1995: 58)

Cury propõe superar a noção de causa pela de mediação, lembrando que as relações não têm uma direção determinística unidirecional, e acrescenta que "se os modos de produção são mediados entre os homens, os homens mediados podem se converter em mediadores entre a estrutura econômica e um novo homem" (Cury, 1995: 65). Desta maneira, se estabelece um protagonismo para os homens como sujeitos de novas relações sociais, sujeitos capazes de negar o status quo e a ordem existente, anunciando e produzindo o novo.

A estreita relação entre educação e estrutura social e a sua interpretação como instrumento de mediação das relações sociais, remete à compreensão da educação como "um saber sempre referido a um fazer" e que "se alimenta da tensão entre a melhoria da força de trabalho e o modo de realização dessa melhoria, inerente ao capitalismo" (Cury, 1995: 74).

Assim, no interior do processo de trabalho, estaria aberta uma perspectiva para a realização da função política da educação, possibilitada pela ação de sujeitos sociais, que, no exercício do seu trabalho, estão organicamente vinculados a uma classe, e, no desempenho de sua tarefa, agregam elementos do econômico, do social e do político, realizando a função de porta-vozes através do seu trabalho. Eles atuam na formação e organização de uma consciência de classe, possibilitando, por seu turno, o avanço na conquista de uma maturidade ideológica transformadora.

Sendo o ensino e a escola as principais referências desta investigação, consideramos oportuno introduzir no quadro de referência algumas questões que embasam o fenômeno educativo, entendendo-o como um momento e um instrumento de tradução das propostas que se realizam através das programações escolares e que deve ser compreendido como objetivação da produção intelectual dos grupos que conformam as instituições pedagógicas em um determinado momento, portanto, fruto de relações sociais.

É também em Cury que vamos encontrar uma leitura do fenômeno educativo, desenvolvida a partir da reflexão de que é necessário avançar no modo próprio de compreender a educação através de um conjunto de elementos, classificados pelo autor como dialeticamente complementares e contraditórios e que the conferem concretude. Tais elementos estão assim apresentados por 
Cury: idéias pedagógicas, instituições pedagógicas, agentes pedagógicos, material pedagógico e ritual pedagógico.

As instituições pedagógicas são entendidas como "organizações culturais (no seu sentido mais amplo), a serviço das ideologias que a veiculam através de instrumentos de difusão, entre os quais estão os agentes pedagógicos, o material pedagógico e o ritual pedagógico" (Cury, 1995: 95). Nessas instituições se realizam as idéias pedagógicas, em torno das quais convivem, dialeticamente, o caráter progressista com o conservador, o novo e o velho, o dominante e o dominado. As instituições pedagógicas são espaços em que as situações contraditórias são consideradas germes dos processos de criação.

Entre os materiais pedagógicos, o currículo e o método se destacam como meios importantes de construção das propostas pedagógicas. Na visão de Cury, esses elementos guardam um caráter de complementaridade entre si e, nas suas especificidades, é possível entender o currículo como instrumento mantenedor ou transformador da ação pedagógica, e o método, como "uma ação em execução em que os fins explícitos ou implícitos são, ao mesmo tempo, condição e resultante da ação" (Cury, 1995: 111).

Os agentes pedagógicos, inseridos nas várias etapas do processo de trabalho, no plano da educação, estão representados pelos docentes, coordenadores, inspetores, orientadores, supervisores, sugeridos pela organização do trabalho, instalada nas organizações. Os agentes pedagógicos seriam, segundo Cury (1995: 113), "os divulgadores mais imediatos da concepção de mundo que buscam o consentimento ativo e coletivo das classes sociais, em função do projeto hegemônico existente".

O ritual pedagógico complementa o conjunto de referências da caracterização do processo pedagógico adotada neste trabalho, abrangendo o pessoal, a organização burocrática, os controles e as provas. Tais elementos envolvem a organização burocrática da escola (horários tempos, normas de conformidade, calendários). Também integram esse campo os programas e os conteúdos, que, ao lado dos sistemas de avaliação, são possibilidades de veiculação de uma linguagem não verbal que se expressa por meio de comportamentos sociais concretos, transmite normas e valores e pode confirmar relações estabelecidas.

Como os outros elementos, os rituais pedagógicos devem ser compreendidos na dimensão de escola, como espaço de reprodução ou recriação de práticas, sofrendo, eles mesmos, as influências do processo social ao qual ela está submetida.

Nessa instituição escolar, a experiência de vida de uma classe está valorizada como um momento pedagógico de intensa significação, denominado por Cury (1995: 97-98) "instituição pedagógica elementar", implicando a realização da tarefa pedagógica em uma oportunidade para "elevá-la, transfor- 
mando-a, em conhecimento, capaz de gerar, além do pensamento, uma ação política organizada".

Essa perspectiva de escola considera também que a maior ou menor importância dela no plano social está relacionada à sua "situação e historicização, no contexto de uma formação social específica”, o que poderá ser refletido através do "grau de elaboração de um pensamento político que ela veicula", e no potencial de "obstaculização e facilitação da transformação social" (Cury, 1995: 104).

Desta forma, podemos compreender como em pleno contexto de ditadura política, de falta de liberdade e garantia plena aos direitos civis, foi possível, como veremos no capítulo 3, produzir propostas de educação profissional para a saúde mais afinadas a teorias e metodologias progressistas, cujas práticas apontavam para a existência de algo mais que um aluno-produto, alheio ao processo de trabalho.

Como estruturas dinâmicas do processo social, e à luz desse referencial teórico, as escolas e os cursos focalizados pelo estudo devem ser entendidos como parte de um processo educativo mais ampliado, no campo da formação em saúde pública (coletiva), e com ele se relacionando nas sucessivas conjunturas, na produção de propostas ligadas à preparação da força de trabalho e à formulação de políticas de saúde, o que pode ter lhes conformado um perfil determinado no conjunto de centros formadores em saúde pública/coletiva do país.

No espaço ampliado, a possibilidade de produção de alguns centros formadores pode ultrapassar os limites das salas de aula, ou mesmo dos espaços tradicionais de configuração de sua estrutura como escola local. Nessa perspectiva, se expande também o potencial de interlocução de suas propostas no interior do campo da saúde e na relação com outros campos de interface, referidas às suas características de escolas nacionais, o que lhes confere a possibilidade de recriação de práticas, e lhes agrega um potencial de colaboração com outras instituições de ensino ou de serviço, inseridas nas conjunturas determinadas. A configuração assumida pelas escolas nacionais possibilitou uma atuação em rede em que os vínculos se multiplicam, impulsionando os produtos da convivência da política com o desenho de processos pedagógicos, muitos dos quais refletidos nos currículos, como também na formação de professores e das estruturas. A multiplicação dessas possibilidades favoreceu a constituição de um embrião de um sistema nacional de formação em saúde pública.

\section{Da tensão do campo às possibilidades da rede}

Para compreender a dinâmica dos processos associativos e de colaboração, na dimensão pedagógica apontada, tomamos inicialmente o ensino da 
saúde pública no Brasil como o nosso campo de referência maior, para, a partir dele, investigar a existência de relações formais ou informais de associação, no seu interior, consideradas as diferentes escolas de saúde pública em apreço. Recorremos aqui aos conceitos de campo e rede, identificando os elementos teóricos que possam contribuir para a recuperação de fenômenos presentes ou subjacentes à realidade estudada.

o conceito de campo está muito identificado ao pensamento de Bourdieu. O autor considera que a adoção do conceito de campo permite romper com vagas referências comumente adotadas para o mundo social, como "contexto", "meio", "fundo social", dentre outras expressões, permitindo a convivência de dominantes e dominados, com suas respectivas vanguardas, suas lutas subversivas e seus mecanismos de reprodução (Bourdieu, 1990: 169).

A questão do poder se expressa através de práticas comuns ao campo científico, como o poder de publicar ou de recusar publicação, de transferir poder dos mais velhos para os mais jovens, através de comentários elogiosos, dos prefácios, dentre outras práticas que foram traduzidas por Bourdieu como "poder de acumular capital", o que abrigaria, portanto, relações de força, estratégias, interesses etc. Nesse caso, o campo aparece como o lugar de relação de força que se impõe a todos os agentes que nele penetram.

No interior do campo, "cada um dos agentes investe a força (o capital) que adquiriu pelas lutas anteriores, em estratégias que dependem, quanto à orientação, da posição desse agente nas relações de força, isto é, do seu capital específico" (Bourdieu, 1990: 171-172), que pode opor vanguardas renascentes a vanguardas consagradas.

O movimento que se organiza no interior do campo pode favorecer 0 poder de nomear até mesmo "o inominável, o que ainda não foi percebido ou que está recalcado". As palavras fazem com que "sejam vistas ou previstas coisas que só existiam no estado implícito, confuso, quando não recalcado" (Bourdieu, 1990: 179).

Para efeito de melhor compreensão, Bourdieu (1983) estabeleceu o que chamou de leis gerais dos campos. Essas leis expressam características de fenômenos do seu funcionamento assim sumarizadas: 1) os campos diferentes possuem leis de funcionamento invariantes, permitindo avançar o conhecimento sobre os mecanismos universais dos campos, que se especificam em variáveis secundárias; um campo se define através dos objetos de disputas e dos interesses específicos que são irredutíveis aos objetos de disputas e aos interesses próprios de outros campos e que não são percebidos por quem não foi formado para entrar nesse campo; 2) a estrutura do campo é um estado da relação de força entre os agentes e as instituições em torno dos quais o capital específico acumulado nas lutas anteriores, permite a orientação de estratégias 
ulteriores; 3) todas as pessoas que estão engajadas num campo têm um certo número de interesses fundamentais em comum, daí a cumplicidade subjacente a todos os antagonismos; 4) os recém-chegados ao jogo que se estabelece no interior do campo devem reconhecer o valor do jogo e os seus princípios de funcionamento. Nesse sentido, as estratégias de subversão empreendidas pelos que se propõem a realizar revoluções no campo se mantêm dentro de certos limites e de outro modo também buscam no passado suas referências para jogar no presente; 5) o habitus de profissional previamente ajustado às exigências do campo vai funcionar como um instrumento de tradução. ${ }^{10}$

A par dessas características que nos permitem compreender a configuração dos campos, é possível depreender a existência de um movimento de articulação entre elas, que se traduz no jogo de poder. Nele, a ortodoxia se relaciona com a entrada de novos atores com menos capital, dispostos a subverter a ordem para construir uma ruptura crítica. Esse processo "está freqüentemente ligado à crise, e, juntamente com a doxa, faz com que os dominantes saiam de seu silêncio, impondo-lhes a produção do discurso defensivo da ortodoxia, visando a restaurar o equivalente da adesão silenciosa da doxa" (Bourdieu, 1983: 90).

Assim, tomamos como referência o conceito de campo, que se expressa em um espaço de relação de idéias, pessoas e instituições, em que interagem novos e velhos atores sociais com suas respectivas contribuições, e onde são empreendidos esforços de renovação, na luta entre o passado e o futuro, entre a heresia e a ortodoxia, que é mediado pela relação de seus membros, numa convivência onde também se misturam conflitos e cumplicidades, num sistema de esquemas geradores de estratégias.

A literatura que bebeu nas águas das análises de Sergio Arouca (O Dilema Preventivista, 1975) e de Cecília Donangelo (Saúde e Sociedade, 1976) - que constituíram as bases de um movimento reformador no campo do pensamento social em saúde, por exemplo - contribuiu em muito para a produção do campo da saúde coletiva, em um movimento genuinamente nacional de revisão das bases teóricas e práticas da saúde pública mais tradicional, ainda inspirada em uma noção higienista e com um recorte de gestão mais governamental.

A capacidade de interlocução desenvolvida no interior do campo da saúde coletiva no Brasil se apresenta como uma expressão importante na literatura. Para entender as conexões que se estabeleceram entre grupos, projetos e instituições, optamos pelos estudos de laboratório que utilizam a noção de rede.

\footnotetext{
${ }^{10} \mathrm{~A}$ teoria do habitus visa a fundar a possibilidade de uma ciência das práticas que escape à alternativa do finalismo ou mecanicismo (Bourdieu, 1983).
} 
Pela expressão e atualidade dos estudos efetuados nessa área, consideramos uma referência importante para facilitar a compreensão de alguns processos associativos empreendidos pela saúde pública (coletiva) no período estudado.

Callon (1989: 21) entende o laboratório envolvido em uma "cadeia de mediadores" que conforma uma "cascata de porta-vozes", capaz de mobilizar "atores, aliados ou adversários potenciais, seres humanos ou não, se encontrando traduzidos no laboratório, sob a forma de representantes raros, próximos, concentrados, accessíveis e manipuláveis". Sua contribuição se inscreve na produção recente da sociologia da ciência, que enfatiza a noção de parceria e de espaços ampliados na produção da tecnociência. Para embasar essa perspectiva, o autor define o laboratório extenso em oposição ao laboratório restrito, justificando, no primeiro, a inclusão de interlocutores e parceiros na composição da sua força de trabalho, pelo papel que desempenham na definição dos conteúdos das pesquisas, na orientação dos programas e mesmo na avaliação dos resultados. No laboratório restrito estariam apenas os seus membros oficiais.

Essa vertente da discussão tem permitido refletir sobre novas formas de organização do trabalho nos laboratórios e compõe um corpo de conhecimentos que embasa a noção de redes sociotécnicas, entendidas como "uma associação de elementos de ordem técnica, econômica, jurídica e política que permitem viabilizar a produção de conhecimentos" (Teixeira, 1994: 13). Nessa compreensão, o laboratório adquire vida interna (laboratório restrito) onde os pesquisadores, professores, alunos e funcionários, e até mesmo os equipamentos ali localizados se relacionam ou estabelecem conexões, com o que se configura como laboratório ampliado, organizando para além dos seus muros as contribuições essenciais ou complementares à produção daquela equipe do laboratório restrito.

A noção de laboratório, nessa perspectiva, proporciona elementos que estão refletidos na dependência e, ao mesmo tempo, no potencial que tais parcerias agregam à sua produção. Assim, o trabalho realizado por determinada equipe no laboratório de pesquisa pode ser visto pela essencialidade do trabalho do pesquisador, aparentemente solitário, mas não prescinde de contribuições quanto à manutenção dos equipamentos que utiliza, ao pagamento das bolsas de seus alunos e colaboradores, à energia elétrica consumida, às produções compartilhadas em arquivos com informações importadas de outros espaços pela via da internet, dentre outras possibilidades ilustrativas dessa conexão.

A aplicação desses conceitos, nas diversas áreas, tem ampliado a discussão, a exemplo das redes de cooperação apresentadas por Vinck, como uma alternativa de cooperação entre projetos colaborativos. Para ele, "o laboratório não é necessariamente associado a um lugar fixo; ele é antes de tudo um 
dispositivo capaz de importar e deslocar fenômenos, assim como exportar e deslocar produtos científicos" (Vinck, 1992: 97).

Os estudos deste autor sobre o tema apontam para a valorização dos conceitos de densidade e centralidade. A densidade está referida à freqüência das relações entre indivíduos e grupos, determinando a sua identidade e coerência como grupo. A sua adoção, como critério de gestão dos processos em rede, permite "acompanhar as transformações dos grupos, sua emergência, extensão, fusão, cisão, germinação, recessão e dissolução" (Vinck, 1992: 88). A centralidade fornece a medida das relações de um indivíduo ou de um grupo com outros indivíduos, por referência a um grupo considerado como central.

A reinterpretação desses conceitos, à luz dos estudos de rede, supera a visão de rede de relaçóes como algo que se processa espontaneamente. Tal conceituação permite introduzir a idéia de gestão de processos em rede, com a possibilidade de efetuar monitoramento das produções que oportunizam a recriação dos fenômenos que se processam em seu interior, com possibilidades de mover os obstáculos que se apresentam como limites à movimentação do campo, e de seus atores em conexão. Problemas identificados nos espaços de produção dos laboratórios restritos podem ser comuns a múltiplos espaços, mesmo dentro do laboratório ampliado, podendo, contudo, ser identificados, recortados, processados, à luz da sua significância no interior da rede, permitindo a convocação de outros atores para o seu equacionamento. De outro modo, esse processamento pode favorecer à produção de novos materiais, que retornam para a rede como contribuição mobilizadora de um outro ciclo de elaboração. Nessa perspectiva está sempre presente a possibilidade de recriação e mobilização, com a recriação permanente de práticas associativas e a agregação da capacidade de movimento à rede de cooperação.

Outra dimensão dos estudos de rede diz respeito à dinâmica dos seus atores e à diferenciação de alguns papéis no interior dos grupos. A relação interna ou externa implica o aparecimento de posturas diferenciadas, tomadas por atores que ampliam a capacidade de diálogo daquele grupo, e dele recebe a delegação para representá-lo em algumas situações. Nesse caso, "o representado é a fonte de poder que anima o representante" (Teixeira, 1994: 20).

Callon (1989: 16) discute assim a vinculação da noção de porta-voz à idéia de representação:

todos os bens, sobre os quais um laboratório age, mobiliza, transforma e fabrica, constituem, qualquer que seja a categoria à qual ele pertença, portavozes ou representantes que, logo que são mobilizados, mobilizam com eles todos os atores humanos ou não humanos que eles representam. 
O laboratório é, assim, o lugar onde interagem "redes inteiras que são permanentemente mobilizadas por um punhado de porta-vozes" (Callon, 1989: 22).

Teixeira (1994) detalha o conceito de porta-voz, incluindo os artefatos tecnológicos, as inscrições tecnocientíficas, as competências e as verbas, e propõe o seu "esquartejamento" como "um mero artifício metodológico", ressalvando que nunca o encontraremos atuando isoladamente.

A autora toma um centro de pesquisa como local de referência para concretização desse conceito e adota a seguinte classificação: os artefatos, elementos não humanos (equipamentos, materiais e substâncias); as notas, tabelas, gráficos, relatórios e artigos estariam entre as inscrições tecnocientíficas; as competências estariam representadas pelos pesquisadores, técnicos, pelo corpo administrativo e pelo conjunto de informações, assim como os textos produzidos pelas equipes; e as verbas viabilizariam a compra de equipamentos, a contratação de pesquisadores e técnicos, como também o investimento na qualificação de pessoal interno.

A interação desses elementos passa a ser essencial na construção e consolidação de projetos em parceria, no interior de um campo, e "traduz-se por uma sucessão de negociações que envolvem aliados e opositores, em um campo nem sempre favorável" (Nunes \& Teixeira, 1996: 211). O desenvolvimento dos projetos está assim associado a uma seqüência de negociações, que começa com a problematização e envolve os elementos dos diversos grupos, dando início a uma seqüência de operações de tradução, ao longo das quais os objetos e produtos se redefinem, até constituírem o produto final (Vinck, 1992).

Os campos onde se processam as elaborações e reelaborações de projetos, palco, portanto, das sucessivas negociações, reúnem atores heterogêneos, que vivenciam relações assimétricas. O avanço das negociações demanda um esforço importante de alguns atores que atuam no monitoramento dos projetos. É nessa perspectiva que se insere o ator-rede, que se diferencia dos demais pela sua condição de firmar posições em seu campo de relação/atuação, articulando aliados e desarticulando oponentes (Nunes \& Teixeira, 1996).

A noção de ator-rede tem sido considerada importante no debate da sociologia da ciência, por abrigar uma gama de fenômenos que facilita a compreensão de espaços que se ampliam. Pela densidade das suas contribuições ao campo com o qual se relacionam e interagem; esses espaços estariam representados por um conjunto constituído de elementos heterogêneos, incorporando cientistas ou não cientistas envolvidos por uma determinada tarefa comum, denominada de concepção estendida de redes sociais (Vinck, 1992). o ator-rede desempenha um papel ativo na relação entre laboratório restrito e laboratório ampliado, emprestando sua densidade e mobilidade à dinâmica dessas relações. 
Para Oliveira (1997: 26), "o conceito de ator-rede permite operar deslocamentos de simples análises locais para questões macro sociais ou econômicas, sem ter que fazer distinções a priori entre o que é cognitivo ou social, material ou imaterial, humano ou não humano, conteúdo ou contexto".

No interior da rede,

o ator em si é uma rede, pela qual circulam uma ampla diversidade de elementos, visões de mundo e modos de conduta (...) a partir dos exercícios de mobilização e enredamento os atores constroem redes complexas de relações, marcadas pela heterogeneidade, as quais sustentam o processo de construção de tecnologias, que se estende para além dos limites físicos dos laboratórios restritos. (Teixeira, 1997: 10-11)

Conseqüentemente, a noção de laboratório extenso expressa essa rede complexa e extremamente heterogênea de atores humanos e não humanos, articulada e mobilizada por um ator-rede.

O debate reúne uma bibliografia extensa com múltiplas aplicações e retrata a capacidade de renovação da discussão da associação entre pessoas, projetos, idéias e instituições. Vale a pena ressaltar a importância dos elementos aqui apresentados como referentes que poderão facilitar a compreensão de fenômenos de aproximação entre pessoas e grupos, mediados por conexões entre projetos e instituições, em sucessivas operações de tradução que vão moldando estratégias de parceria peculiares a cada contexto e a cada grupo considerado, revelando atores, que atuam na dinâmica dessas operações.

Esse quadro de referência nos convida a procurar entender os contextos onde se desenvolveram as 'cenas' que permitiram a construção de uma ambiência na realidade brasileira, onde se incluiu o objeto dessa investigação. A efervescência gerada pelas dificuldades que se estabeleciam nos espaços de convivência da sociedade naquele momento parece ter se constituído em contraposição aos limites estabelecidos no plano formal das instituições, possibilitando o surgimento de "novos personagens", novos sujeitos sociais que entraram em cena (Sader, 1988).

Para melhor compreensão do contexto, consideramos exemplar o pensamento de Sader, que retrata a riqueza das oportunidades surgidas na adversidade do governo militar, quando seus opositores construíram um caminho pela política, cuja expressão, entre outras, foi a adesão de grupos dos serviços de saúde, instalados tanto nos serviços quanto nas universidades. Muitos deles tinham como leito a formação de recursos humanos como um ambiente de criação e aplicação de práticas políticas, tendo como imagem objetivo a necessidade de avançar na construção da saúde com democracia.

A obra de Sader sobre o tema abrange parte de um período coincidente com aquele estabelecido por esta investigação. Sua obra foi capaz de recons- 
truir um movimento, cuja ação coletiva e organizada de trabalhadores permitiu o deslocamento da cena para o pólo da prática política, estabelecendo a vivência de um novo cotidiano, que se renovou no interior do sindicalismo, nas relações com a Igreja e na crítica à inércia da esquerda. Analisando a conjunção desses fatores, o autor concluiu que "a autonomia dos movimentos rompeu com a tradição política de tutela e de cooptação e por isso mesmo, permitiu a ação política criar novos lugares para exercitar-se" (Sader, 1988: 11).

Eder Sader (1988: 10) reviveu os movimentos sociais populares da região de São Paulo, "que puseram novos personagens na cena histórica brasileira, entre 70 e 80, criando condições para o exercício da democracia". Essa contribuição evidenciou o que Marilena Chauí denominou de "fio condutor desse trabalho", no prefácio do livro de Sader, traduzindo tais movimentos como lócus coletivo então privilegiado para a "criação de um novo sujeito social e histórico", assim caracterizado pela autora: novo, porque criado pelos próprios movimentos sociais populares do período, e não designados por teorias prévias; porque também se trata de um sujeito coletivo e descentralizado; porque é um sujeito que, embora coletivo, não se apresenta como portador da universalidade definida a partir de uma organização determinada que operaria como centro, vetor e telas das ações sociopolíticas e para a qual não haveria propriamente sujeitos, mas objetos ou engrenagens da máquina organizadora.

Nesse sentido, "o novo sujeito é social; são os próprios movimentos sociais populares, em cujo interior, indivíduos, até então dispersos e privatizados, passam a definir-se, a reconhecer-se mutuamente, a decidir e agir em conjunto e a redefinir-se a cada efeito resultante das decisões e atividades realizadas" (Sader, 1988: 11).

Sader justificou as suas conclusões pelo exame da crise da Igreja, que teve como conseqüência a reformulação de seu discurso, a crise das esquerdas configurada por derrotas anteriores e impasses internacionais com a matriz discursiva marxista e a crise do sindicalismo que, para ele, resultou numa renovação da "matriz discursiva do novo sindicalismo", vindo a ocupar um lugar institucional cuja eficácia foi decisiva para "alargar a percepção dos antagonismos que regem a sociedade de classes" (Sader, 1988: 11).

A noção de "sujeito coletivo" então é indicada "para representar uma coletividade onde se elabora uma identidade e onde se organizam práticas através das quais seus membros pretendem defender interesses e expressar suas vontades, constituindo-se nessas lutas" (idem). Dessa forma, o sentido do novo favoreceu o rompimento do silêncio dos grupos organizados, e se estruturou por sinais de resistência que foram se constituindo em "pequenas vitórias".

Esse era um momento de "desconfiança dos sujeitos com relação às instituições políticas e com os sistemas políticos de mediações”, mas, em lugar de 
apatia, ocorreu a valorização das diferenças entre os movimentos, e a busca por autonomia (Sader, 1988 12); os espaços políticos foram recriados com a revalorização do espaço público, no interior dos clubes de mães, das comissões de saúde, das oposições sindicais e os sujeitos dos movimentos passaram a falar em "conscientização", "reflexão crítica" e "socialização do saber", nos correspondentes espaços da Igreja, da esquerda e no sindicato, e os movimentos sociais passaram a operar como "fontes populares de informação, aprendizado e conhecimento políticos, que tendem a ser ampliados e redefinidos pela sua própria prática e dinâmica" (Sader, 1988: 13).

A opção pela contextualização aqui apresentada não pretende aprofundar sociologicamente as teses do autor sobre os movimentos sociais da época, mas trazê-las, para considerá-las relacionadas com as questões abordadas por este trabalho. Quando Novos Personagens Entraram em Cena (Sader, 1988) é uma obra em que se discutem as experiências e lutas dos trabalhadores da Grande São Paulo na década de 70 e que consideramos importante examinar, a fim de iluminarmos possíveis relações entre a concepção de "novos personagens" trazida pelo autor, e o contexto onde se desenvolveu o ensino da saúde pública/ coletiva no período estudado. Como as equipes, os projetos e as instituições se relacionaram com um novo sujeito coletivo e com ele exercitaram formas de criação, cujos produtos como cursos, disciplinas, currículos e métodos mere-
cem ser analisados. 